\title{
Magnetometers for a Geomagnetic and Seismic Combined Survey
}

\author{
L. Benyosef* \\ A. Wiermann* \\ J.R. Carvalho*
}

Recibido en mayo de 2013; aceptado en septiembre de 2013

\section{Resumen}

El Laboratorio de Desarrollo de Sensores Magnéticos del Observatorio Nacional (LDSM/ON) desarrolla y construye sensores y magnetómetros fluxgate de alta sensibilidad utilizando aleaciones amorfas y nanocristalinas. El Equipo de Sismología del Observatorio Nacional conduce estudios sísmicos con datos del Consorcio IRIS. Seis nuevas estaciones con sismómetros de banda ancha y magnetómetros de alta resolución están siendo instalados en el Estado de Río de Janeiro. Para esto, magnetómetros sensibles han sido especialmente desarrollados utilizando sensores con núcleos nanocristalinos ( $\mathrm{FeSiCuNbB})$. El sistema registra los datos magnéticos en un rango de $(0,001-100) \mathrm{Hz}$, con resolución de 0.1 nT y ruido de $800 \mathrm{pT}$ (rms).

Palabras clave: Magnetómetro, sensores nanocristalinos, seismo-magnetismo.

\section{Abstract}

The Laboratory of Magnetic Sensors Development (LDMS/ON) from the Observatório Nacional develops and builds high sensitivity fluxgate sensors and magnetometers using nanocrystalline and amorphous alloys. The Seismological Team of the Observatorio Nacional leads seismic studies using data from the IRIS Consortium. Six stations using broadband seismometers and high resolution fluxgate magnetometers to work combined are being installed in the Rio de Janeiro State. The developed magnetometers have high sensitive ring-core sensors made using nanocrystalline $(\mathrm{FeSiCuNbB})$ alloy. The system records magnetic data in a range (0.001-100) Hz with resolution $0.1 \mathrm{nT}$ and noise: $800 \mathrm{pT}$ (rms).

Key words: agnetometer, nanocrystalline sensors, seismo-magnetism.

* Observatorio Nacional de Rio de Janeiro, Rua General José Cristino 77, CEP 20921-400, Sao Cristovao, Rio de Janeiro, RJ, Brasil. 


\section{Introduction}

The Rio de Janeiro state, situated at Brazil southeast region, has a seismic activity characterized by low magnitude events, although there are records of events with magnitude exceeding 4.0 on the Richter Scale.

Due to increasing off-shore construction activities taking place at Campos Basin near the coast of Rio de Janeiro, a detailed and systematic study of local seismic activities becomes of great importance as a tool to help accessing potential impacts and consequent risks over the human activities on the field. In order to start such studies, a network of six broadband seismic stations were built and will be deployed along the region, forming a sensing array focused on local and regional seismic activity, with special attention to offshore originated sources.

The mobilization to install the necessary infrastructure for the seismic stations created also an oportunity to include other instruments, without significative increase in costs.

In recent works (Mueller and Johnston, 1990; Fraser-Smith, A.C., A. Bernardi et al., 1990; Johnston, Mueller, and Sasai, 1994; Fregoso-Becerra, and GarcíaAbdeslem, 2010; Hayakawa and Hobara, 2010; Takla, Yumoto et al., 2011) there are increasing references to some degree of correlation between geomagnetic variation and seismic activities. Mainly for large earthquakes, there are evidence of possible event predictions as magnetic disturbances sometimes happen before the seismic occurrence with a time span that goes from minutes to hours or even days. Studies also show that some local geomagnetic variations may be related to seismic activity as a side effect resulting from piezoelectric properties of magnetic and geological sites (Eleman, 1965; Sasai, 1991). Based on these concepts it was decided to include in each of the six seismic stations a triaxial magnetometer capable of detecting and recording magnetic signals.

The well known fluxgate topology was chosen due its compact size, low consumption and great parameter flexibility (Primdahl, 1970). A range of DC up to 100 $\mathrm{Hz}$ was chosen aiming to match its spectrum with that of the broadband seismometers used. This would allow the investigation of possible direct effects correlating seismic and magnetic phenomena.

\section{Development}

The task for the LDSM was to develop and construct six fluxgate geomagnetometers capable to achieve the following main goals: 


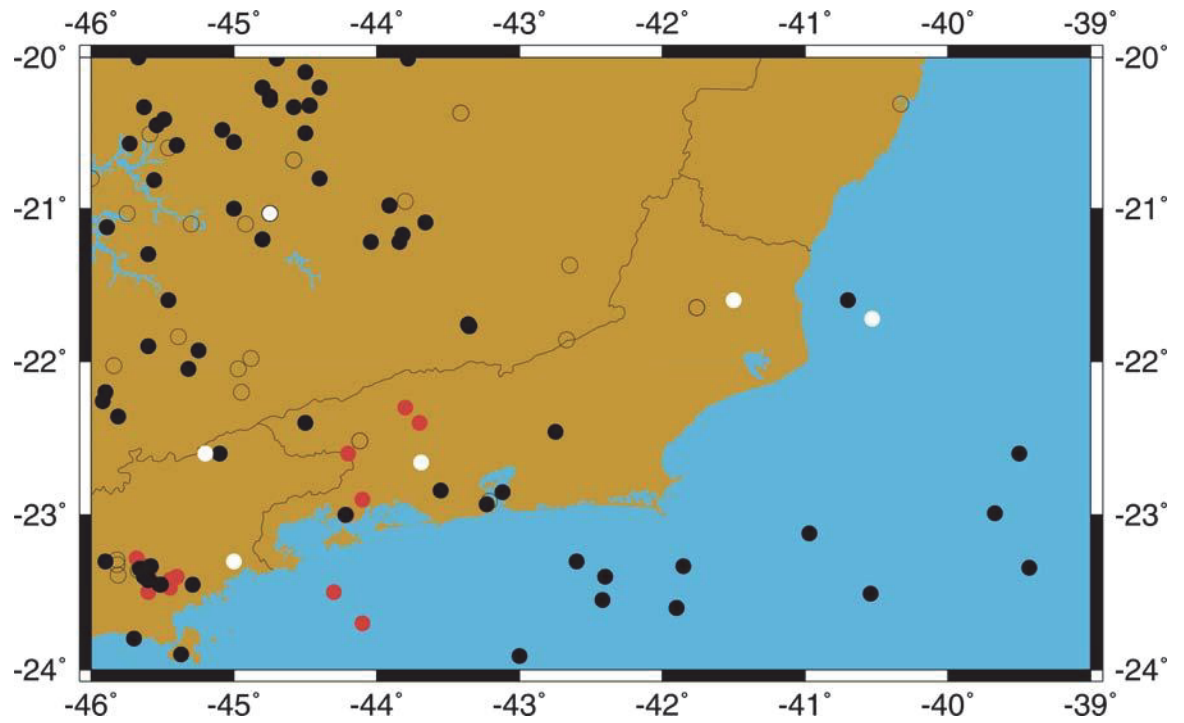

Figure 1. Location of earthquakes in the state of Rio de Janeiro from 1720 to 1995 (source: SBGf).

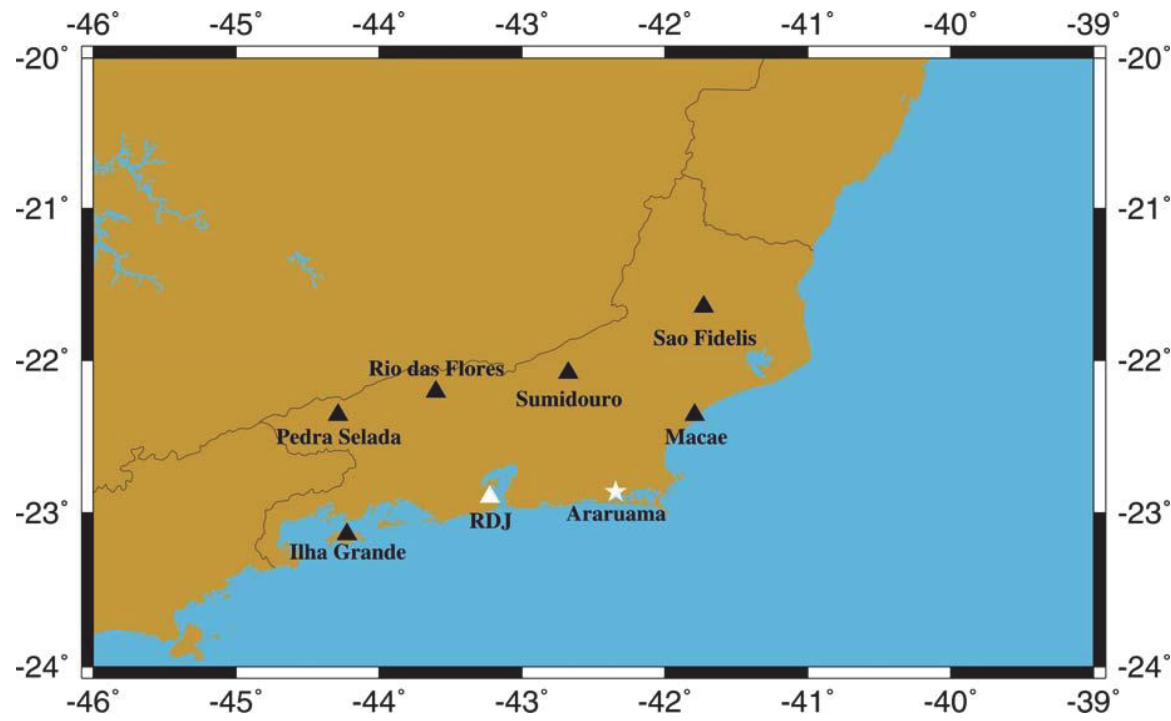

Figure 2. New Rio de Janeiro state seismic network. Black triangles: new proposed seismic stations with magnetometers. White triangle: broadband National Observatory (ON) White star: first new broadband operating since 2012. 
- To create an infrastructure for monitoring seismic and geomagnetic variations from very low frequencies, near dc to $100 \mathrm{~Hz}$ in order to observe possible correlations between them.

- To lead detailed seismic and geomagnetic analysis on the structure and composition of the lithosphere of Rio de Janeiro state to increase the data set for geological and geophysical studies.

The upper frequency band of $100 \mathrm{~Hz}$ is an unusual high frequency for geomagnetometers and for such we start doing tests with different sensor sizes and construction techniques. Special attention was also dedicated to the companion electronics aimed to read and record the triaxial signal with the required speed, low noise, high resolution and sensitivity.

Apart from the electronic processing, the main source of noise in a fluxgate magnetometer is its core material. Three types of noises are produced by the ferromagnetic material: Barkhausen, thermal and magnetostrictive. All those are related to alloy composition, magnetic structures, and mechanical tensions within the bulk material (Nielsen, Petersen, and Herzer, 1994; Benyosef, Teodosio et al., 1995; Benyosef, Teodosio et al., 1996; Perez and Benyosef, 2009).

Several amorphous and nanocrystalline sample materials available at the LDSM were tested and compared searching for a low noise and fast response material, adequate for the proposed sensor.

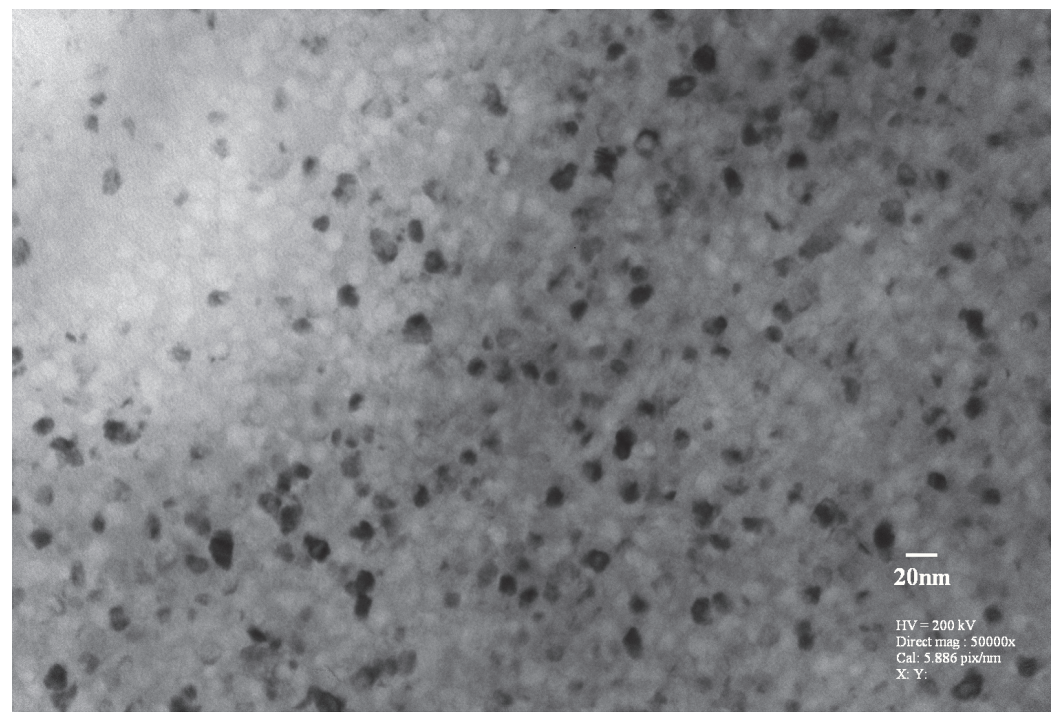

Figure 3. Electron transmition micrography of a nanocrystalline FeSiCuNbB sample Perez, Solorzano and Benyosef, 2009. 
The testes included hysteresis characterization at several frequencies, spectral noise measurements under fluxgate mode (that encompasses the Barkhausen noise) and magnetostriction induced vibration. Each sample under test was assembled as a toroidal core and mounted inside a standard fluxgate coil sensor as Figure 3.
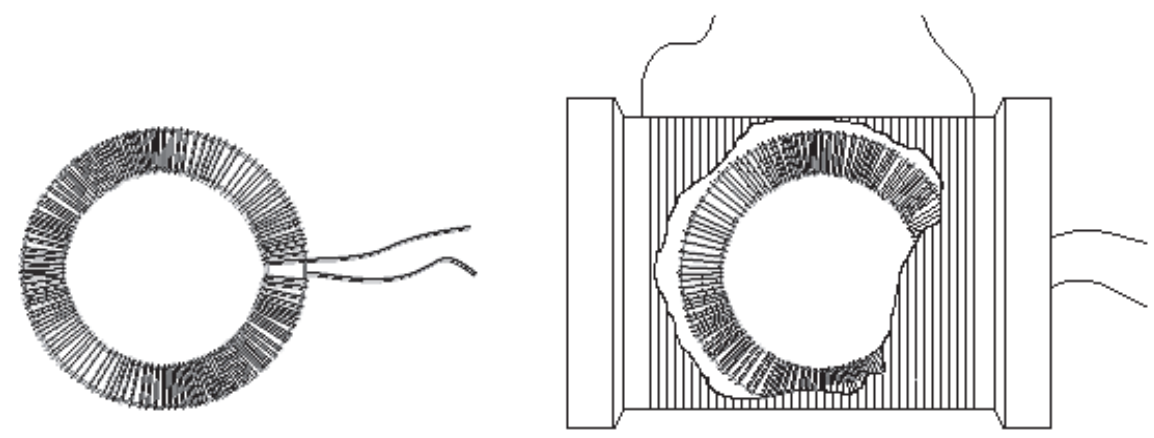

Figure 4. Single axis sensor arrangement for tests (source: LDSM/ON).

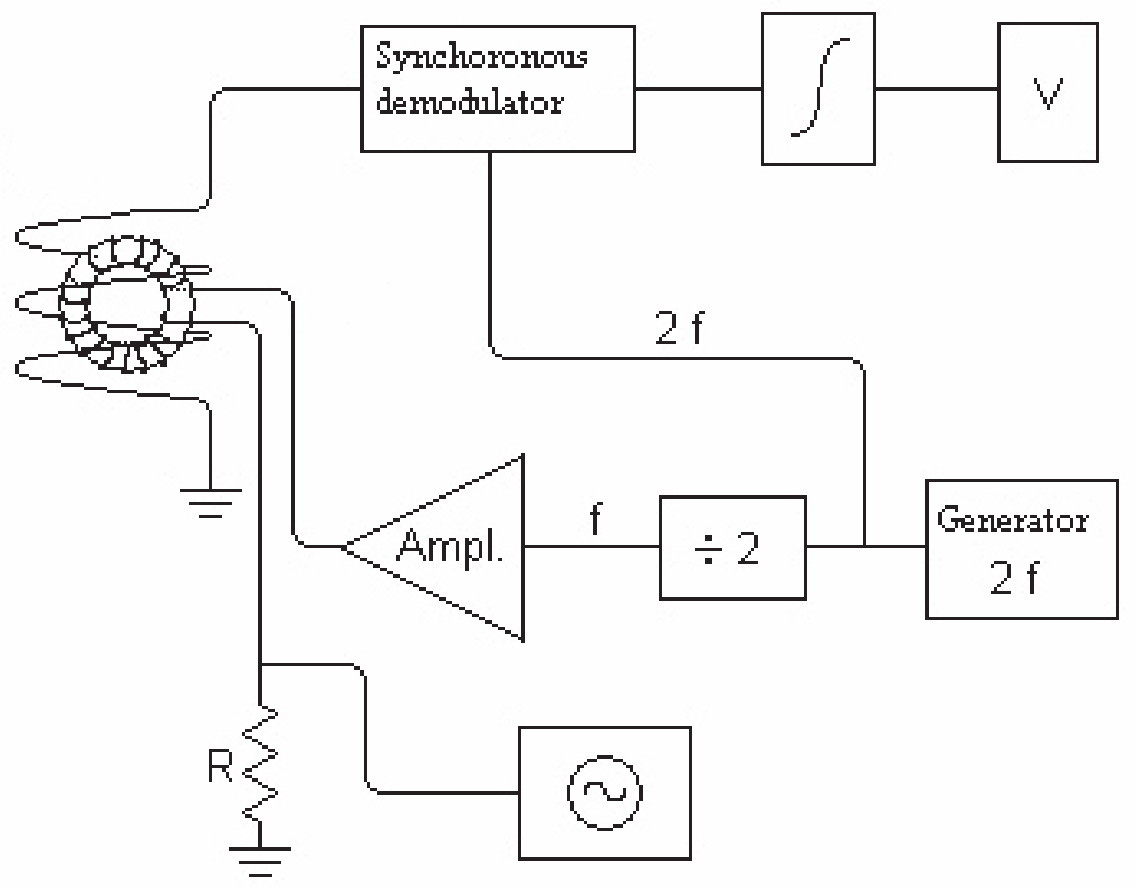

Figure 5. Block diagram for the open circuit fluxgate test bench (source: LDSM). 
The resulting test sensors were then connected to a specially developed open circuit fluxgate. The measurements were performed with a Stanford SR830 DSP lock-in amplifier and a SR760 digital spectrum analyzer (Figure 5).

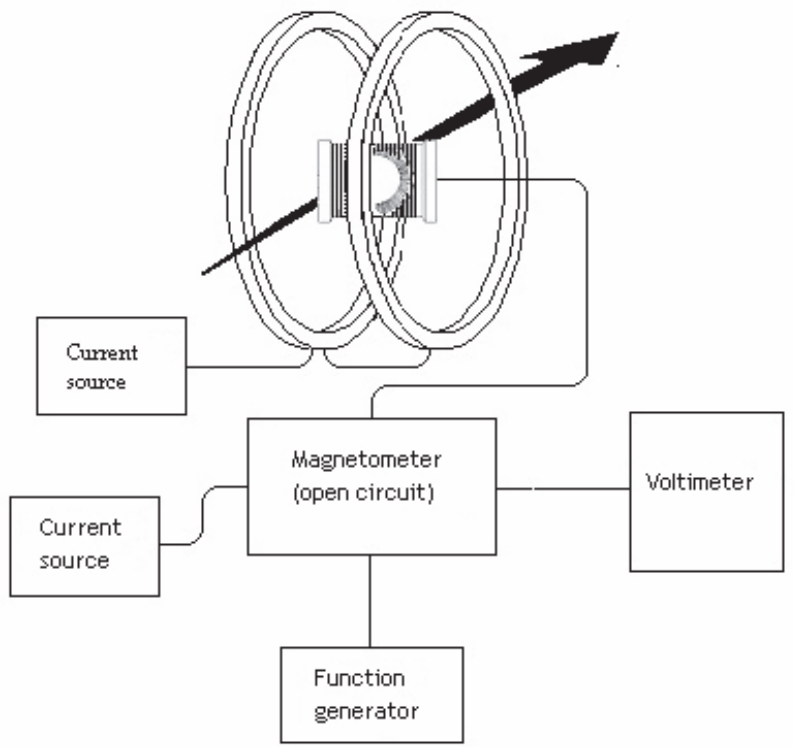

Figure 6. Workbench configuration for linearity and frequency response tests (source: LDSM).
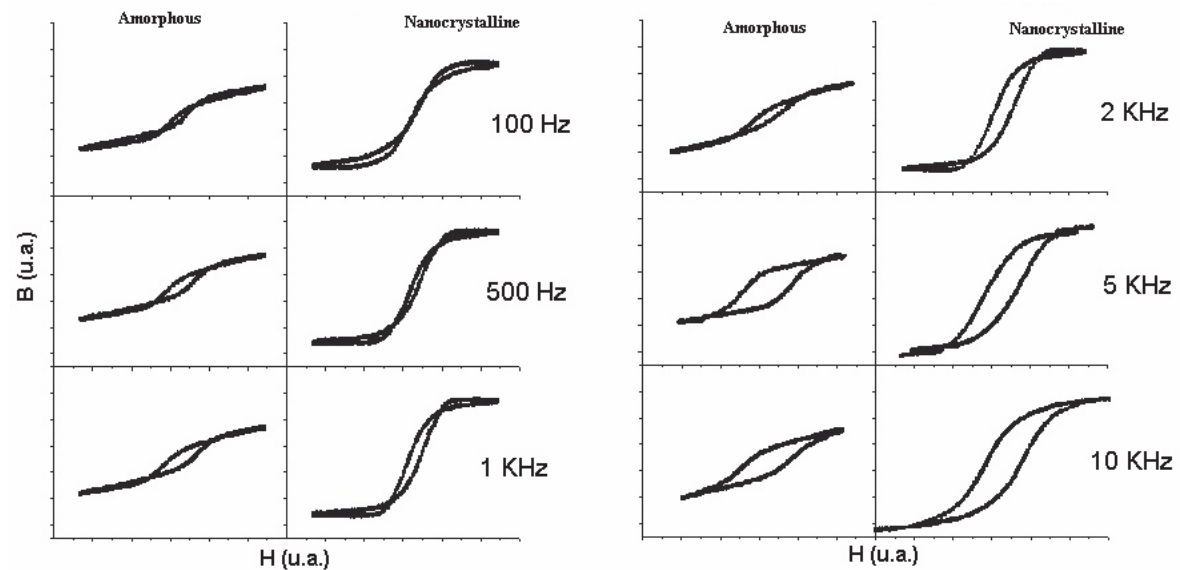

Figure 7. Some hysteresis comparison between amorphous and nanocrystalline materials (source: LDSM/ON). 
Based on our benchmar results the selected material was a nanocrystalline alloy (74.3Fe14.2Si1 Cu3Nb7.5B). This material has been subjected to a special thermal treatment at the LDSM, presenting excellent noise and linearity parameters (Figures 7 and 8 ).

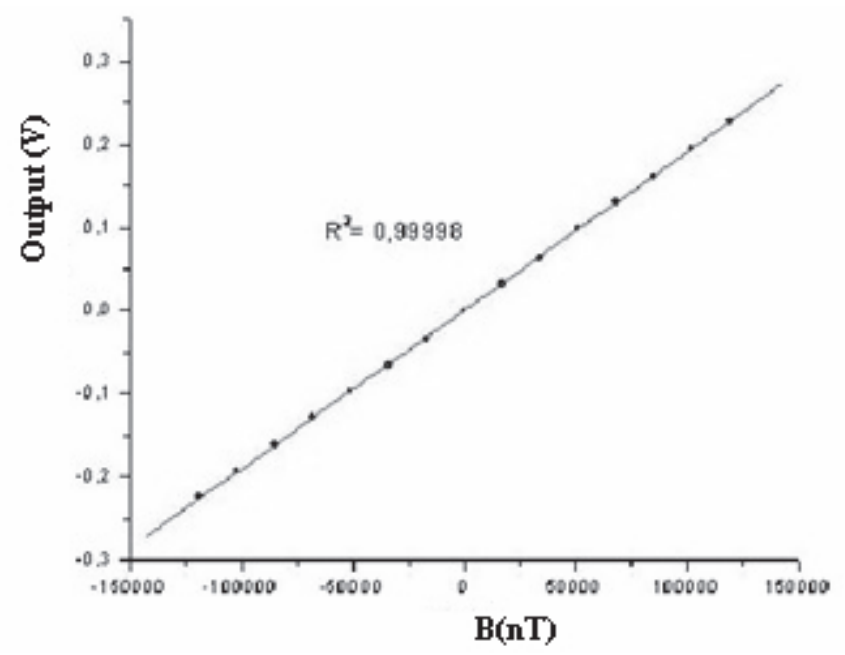

Figure 8. Nanocrystalline sensor (74.3Fe14.2Si1Cu3Nb7.5B alloy) linearity test result. Measurement performed with an open circuit fluxgate test bench and a Helmholtz coil (source: LDSM/ON).

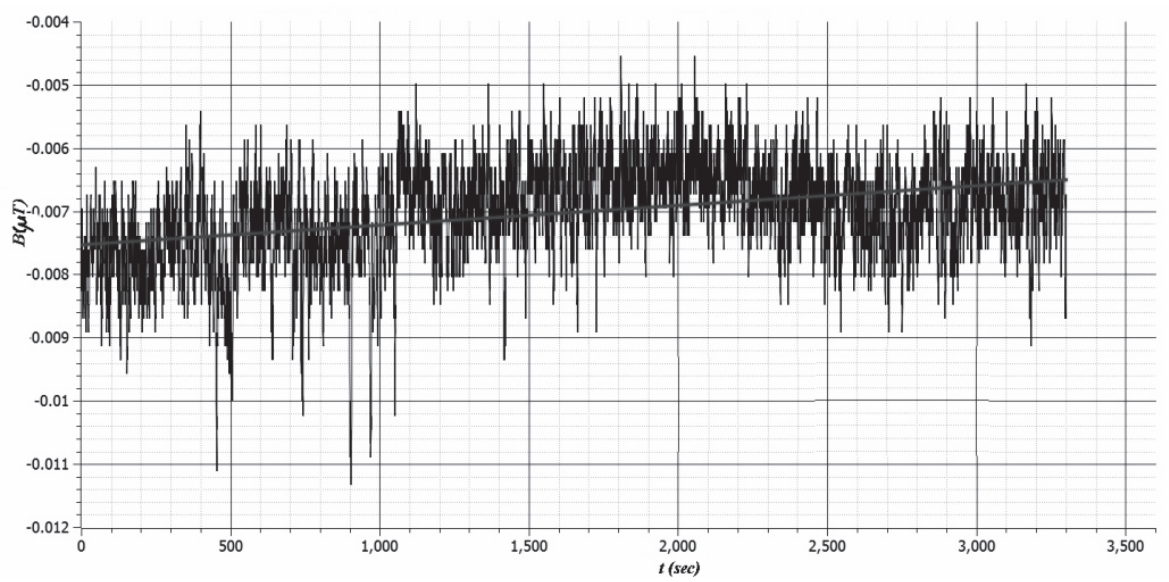

Figure 9. Nanocrystalline sensor (74.3Fe14.2Si1Cu3Nb7.5B alloy) noise test result. Sensor under test installed inside a five layers $\mu$-metal magnetic shield (source: LDSM/ON). 


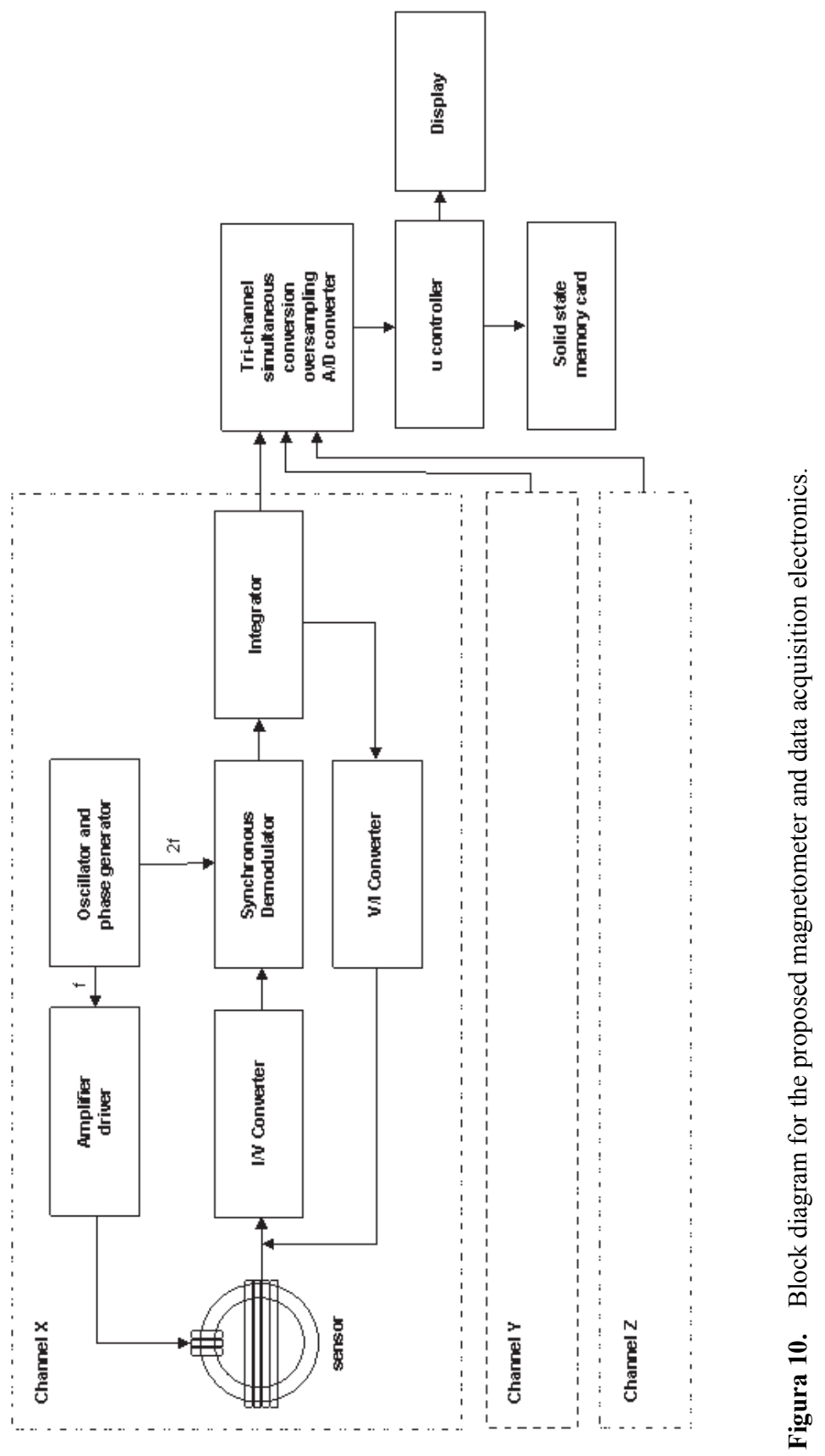




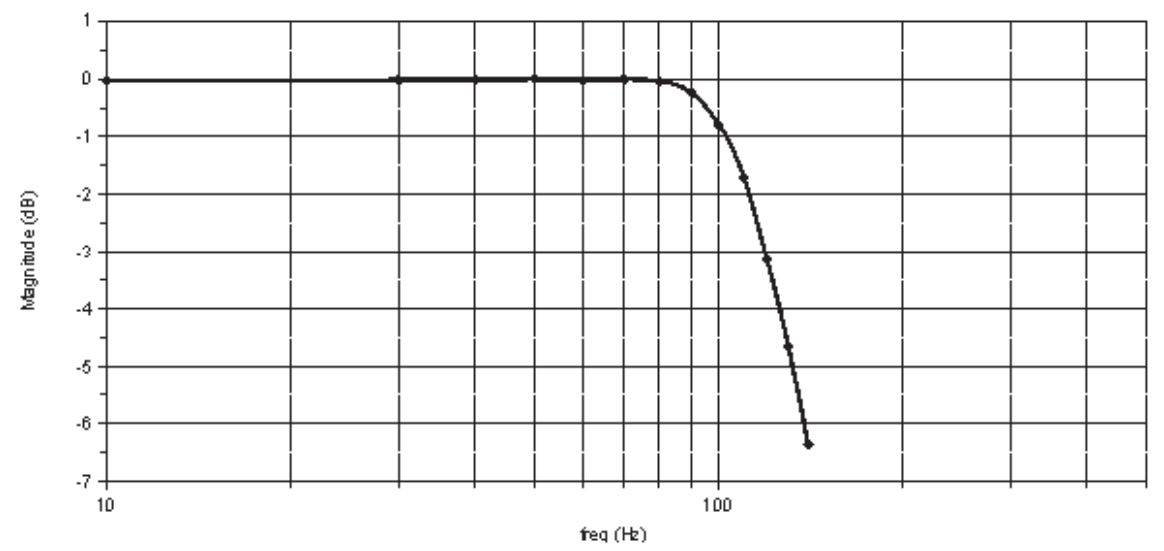

Figura 11. Measured frequency reponse for the developed magnetometer.

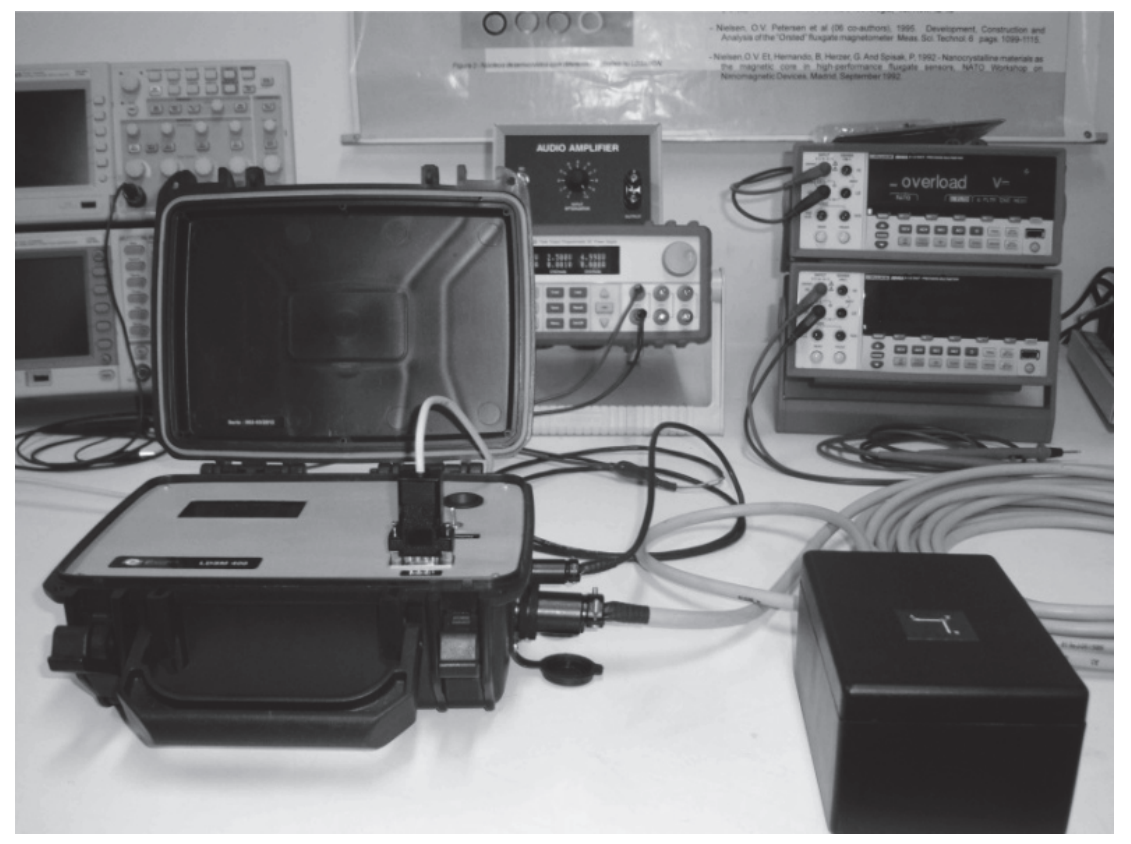

Figura 12. Magnetometer (sensor and electronics) developed by LDSM/ON.

The magnetometer electronics was based on a microcontroller that interfaces to three individual analog to digital converters in a synchronized way producing simultaneous readings for the three components signals at a speed of 250 samples per second. Three fast, high resolution 24 bits CMOS sigma-delta analog to digital 
converter (ADC) were used. The ADC readings are compressed and stored in a SD memory card for posterior processing and correlation with seismic data.

After the core material selection and the electronics assembling, a frequency response measurement was performed. To this test a variable field sweeping from zero to $150 \mathrm{~Hz}$ was produced by a Helmoltz coil, drived with a signal generator and a lab amplifier in current mode.

The final circuit includes also a real time clock for time stamping on recorded data and a provision for connection through an Ethernet interface. This interface can be used in the future for remote control and data acquisition.

\section{Bibliography}

Benyosef, L.C.C., Teodosio, J.R., Taranichev, V.E., Zhalnin, B.V., 1995. "Improvements on CoFeSiB Amorphous Ribbon for Fluxgate Sensor Cores", Scripta Metallurgica et Materialia, Vol. 33, No. 9, pp. 1451-1454.

Benyosef, L., Teodosio, J., Taranichev, V.E., Zhalnin, and Nemova, O. Yu, 1996. "Effect of stress on the magnetic properties of Amorphous ribbons for fluxgate magnetometers", Journal of Advanced Materials, Vol. 3, No. 2, pp. 140-143.

Berrocal, J., Fernandes, C., Bassini, A., Barbosa, J.R., 1996. Earthquake Hazard Assessment In Southeastern Brazil. Geofisica Internacional, Vol. 39, pp. 257272.

Eleman, F., 1965. "The response of magnetic instrument to earthquake waves", Geomag. Geoelectr., No. 18, pp. 43-72.

Fraser-Smith, A.C., A. Bernardi, P.R. McGill, M.E. Ladd, R.A. Heliwell, and O.G. Villard, Jr., 1990. "Low-frequency magnetic field measurements near the epicenter of the Ms 7.1 Loma Prieta earthquake", Geophys. Res. Lett., No. 17, pp. $1465-1468$.

Fregoso-Becerra, E., García-Abdeslem, J., 2010. "A possible seismomagnetic precursor of the El Mayor-Cucapah earthquake (Mw 7.2) of April 4, 2010, Baja California, México", Geofisica Internacional, No. 2, pp. 211-225.

Hayakawa, M. and Hobara, Y., 2010. "Current status of seismo-electromagnetics for shortterm earthquake prediction”, Geomatics, Natural Hazards and Risk, Vol. 1, No. 2, pp. 115-155.

Johnston, M.J.S., R.J. Mueller, and Y. Sasai, 1994. "Magnetic field observation in the near-field the 28 June $1992 \mathrm{Mw} 7.3$ Landers, California, earthquake", Bull. Seis. Soc. Am., No. 84, pp. 792-798.

Mueller, R.J. and M.J.S. Johnston, 1990. "Seismomagnetic effect generated by the October 18, 1989, Ml 7.1 Loma Prieta, California”, Earthquake, Geophys. Res. Lett., No. 17, pp. 1231-1234. 
Nielsen, O.V., Petersen, J.R., Herzer, G., 1994. "Temperature Dependence of the Magnetostriction and Induced Anisotropy in Nanocrystalline $\mathrm{FeCuNbSiB}$ Alloys, and their Fluxgate Properties", IEEE Transactions on Magnetics, Vol. 30, No. 2.

Perez, G. Solorzano, G. and Benyosef, L. 2009. "Production of nanocrystalline 74.3Fe14.2Si1Cu3Nb7.5B alloy for magnetic sensors", $11^{\text {th }}$ International Conference on Advanced Materials.

Primdahl, Fritz, 1970. "The fluxgate mechanism", Part 1, IEEE Trans. Mag. MAG-6.

Sasai, Y., 1991. "Tectonomagnetic modeling on the basis of the linear piezomagnetic effect”, Bull. Earthq. Res. Inst., No. 66, pp. 585-722.

Sousa, J.L. et al., 2007. "Monitoramento sísmico e geomagnético do estado do Rio de Janeiro: Uma proposta cientifica e suas implicações sociais", Projeto FAPERJ

Takla, E.M., Yumoto, K., Liu, J.Y. et al., 2011. "Anomalous Geomagnetic Variations Possibly Linked with the Taiwan Earthquake $(\mathrm{Mw}=6.4)$ on 19 December 2009", International Journal of Geophysics. 